\title{
DÜBLIN
}

Technological University Dublin

ARROW@TU Dublin

Conference Papers

School of Manufacturing and Design

Engineering

2004-01-01

\section{Investigation of Four-wheel Steering Algorithms for a Formula SAE Car}

\author{
Colm O'Kane \\ Technological University Dublin, colm.okane@tudublin.ie \\ Sean Timoney \\ University College Dublin
}

Follow this and additional works at: https://arrow.tudublin.ie/engschmanconn

Part of the Applied Mechanics Commons

\section{Recommended Citation}

O'Kane, C., Timoney, S.: Investigation of Four-wheel Steering Algorithms for a Formula SAE Car. Society of Automotive Engineers Special Publication 2004: Vehicle Dynamics and Simulation (SP-1869). Presented at 2004 SAE World Congress, Detroit, Michigan, March 8-11, 2004.

This Conference Paper is brought to you for free and open access by the School of Manufacturing and Design Engineering at ARROW@TU Dublin. It has been accepted for inclusion in Conference Papers by an authorized administrator of ARROW@TU Dublin. For more information, please contact arrow.admin@tudublin.ie, aisling.coyne@tudublin.ie,gerard.connolly@tudublin.ie.

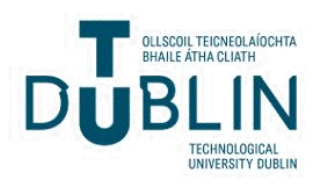




\section{Investigation of Four-wheel Steering Algorithms for a Formula SAE Car}

Colm O'Kane and Sean Timoney

University College Dublin 
All rights resenved. No part of this publication may be reproduced, stored in a retrieval system, or transmited, in any fom or by any means, electromic, mechanical, photocopyng, recording, or otherwise, whou the prior writien permission of SAE.

For permission and licensing requests contact:
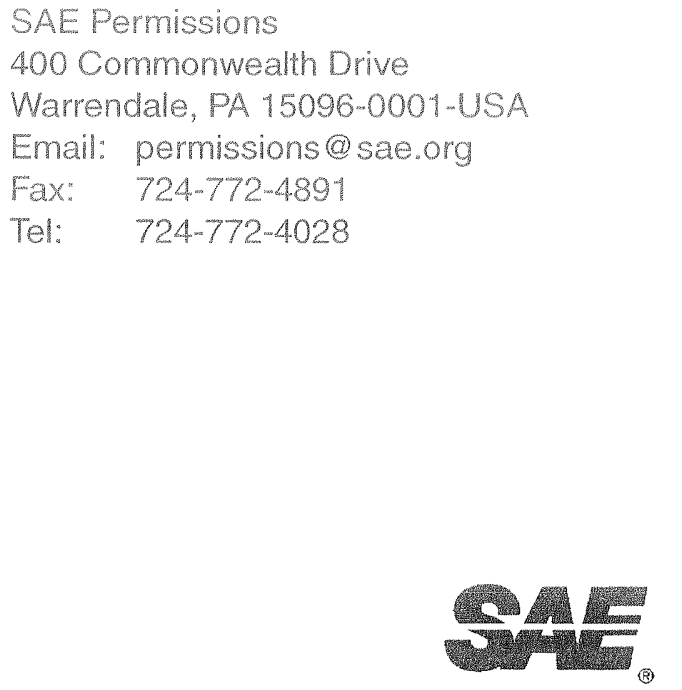

\section{Global Mobililty llatahase}

All SAE papers, standards, and selected books are abstracted and indexed in the Global Mobility Database.

For multiple print copies contact:

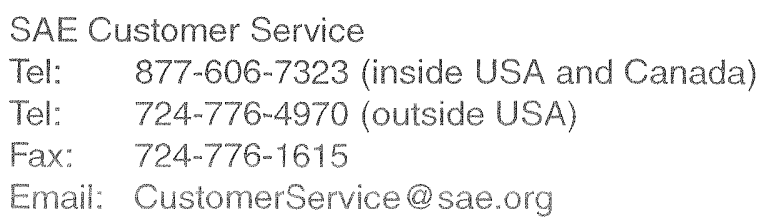

\section{ISBN 0 $7680 m-1319 m$}

\section{Copyright 0 2004 SA E International}

Positions and opinions advanced in this paper are those of the author(s) and not necessarily those of SAE. The author is solely responsible for the content of the paper. A process is available by which discussions will be printed with the paper if it is published in SAE Transactions.

Persons wishing to submit papers to be considered for presentation or publication by SAE should send the manuscript or a 300 word abstract of a proposed manuscript to: Secretary, Engineering Meetings Board, SAE.

\section{Printed in USA}




\section{Investigation of Four wheel Steering Algorithms for a Formula SAE Car}

\section{Colm O'Kane and Sean Timoney}

University College Dublin

Copyright $($ 2004. SAE Intenational

\section{ABSTRACT}

An algorithm was developed for a speed-dependent four-wheel steering system for a Formula SAE car.

A linear bicycle model was implemented using the MATLAB and SIMULINK software packages. Various control laws were investigated for the rear steer angle with the objective of reducing the sideslip angle.

A full 30 model of the vehicle incorporating weight transfer and tire non-linearity was then developed using the DADS software. An algorithm developed using the linear model with the aim of reducing vehicle sideslip angle was implemented in the nonlinear model. It is shown that this algorithm can improve the dynamic performance for both high-speed and low-speed maneuvers.

\section{NOMENCLATURE}

$\begin{array}{lll}A & : & \text { Lateral Acceleration } \\ C_{\alpha 1}: & \text { Front Axle Comering Stifness } \\ C_{a 2}: & \text { Rear Axte Comering Stifness } \\ F_{y 1} \quad: & \text { Front Axle Lateral Force } \\ F_{y 2} \quad: \quad & \text { Lateral Acceleration Response Gain } \\ G_{A} & : \quad \text { Yaw Rate Response Gain } \\ G & \text { Yaw Moment of Inentia }\end{array}$

k : Understeer Gradient

K : FrontRear Steering Ratio

$l_{1}:$ Distance, Front Axle to CG

$l_{2} \quad: \quad$ Distance, Rear Axle to CG (negative)

L : Wheelbase

$m \quad$ : Vehicle Mass

r : Yaw Velocity

$R \quad: \quad$ Tum Radius

u : Forward Velocity

v : Lateral Velocity at centre of gravity

$\alpha_{1}: \quad$ Front Slip Angle

$\alpha_{2}$ : $\quad$ Rear Slip Angle

$\beta\left(\alpha_{c g}\right): \quad$ Vehicle Sideslip Angle

$\delta_{1}: \quad$ Front Steering Angle

$\delta_{2} \quad$ : Rear Steering Angle

$\delta_{s w} \quad: \quad$ Steering Wheel Angle

$\delta_{u} \quad: \quad$ Understeer Angle

$\omega_{f}$ : Angular Velocity of Steer Function 


\section{MTPODUCTION}

\section{AIMS AND OBUECTVES}

One of the most important aspects of a racing car's dynamic behavior is yaw response. This response must combine rapid transients with stability at high speed. The aim is to optimize this response under the constraints of cost, mass, moment of inertia, packaging, elc.

Four-wheel steering (AWS) is currenty being developed as a safely leature in the automotive industry to improve the high-speed stability and low-speed maneuverability of vehicles [1]-5]. In the Formula SAE driving environment, the challenge is lo produce a system that improves dynamic performance under race conditions. Similar constraints apply, athough their relative importance differs.

Generally, 4WS has been investigated in the literature using the linear bicycle model [6]-[8]. This model is limited to the linear region of vehicle dynamics. This paper presents results of a full 3D analysis of the problem. 4WS has also been investigated in the Formula SAE driving regime [9], but with a constant ratio between front and rear steer angle. This research presents an algorithm based on the bicycle model for a speed-varying ratio between front and rear steer angle, and shows the benefits of this ratio in several simulated vehicle tests.

Initial modeling was based on the linear bicycle model and performed in the MATLAB software package. A full 3D dynamic model of the system was also produced using the DADS sofware, which incorporated tire nonlinearity, body roll and weight transfer. A tire model generated from commercial tire data was used. The model was subjected to various handing tests, which were chosen to reflect both tests commonly carried out on vehicles, and the type of challenges to which this type of racing car would be subjected in competition. The results show the potential for improvement of vehicle performance using the 4WS algorithm generated. It is also acknowledged that Direct Yaw Control (DYC) could further improve the vehicle's performance [12]-[14].

\section{COMPUTER MODELING}

Initial modeling was based on equations derived from a free-body diagram of the vehicle during cornering. Several simplifying assumptions were employed to linearize the equations. The effects of both body roll and load transter were neglected, the center of gravity of the vehicle is assumed to be at ground level, and the comering characteristics of the two tires at each axde are lumped together into one. This linear model is often called the "bicycle model" because it assumes only one wheel at each axle. No suspension efrects are modeled and we assume constant forward velociy and linear tre characteristics. It is generally accepted that at lateral accelerations below approximately 0.49 , these simpilying assumptions are acceptable. At lateral accelerations above this figure, the effects of tire characteristics and load transfer can no longer be neglected.

This model was used to examine the effect of three different steering algorithms: front whed steer (FWS), same-phase steering (SP) and opposite phase steering (OP). In each case a linear relationship $(K)$ exists beween front wheel steer angle and rear wheel steer angle $(K=0,0.5$, and -0.5 respectively).

\section{LINEAR MODELING}

\section{THE BICYCLE MODEL}

Two aspects of the linear model were investigated in separate models: namely the frequency response of the yaw rate and lateral acceleration to steer angle, and the steer ratio necessary to minimize body sideslip angle over a range of vehicle speeds.

The equations derived from the bicycle model were implemented in SIMULINK in block-diagram form and the various responses (yaw rate, lateral acceleration and slip angles) to a step steering input were calculated for the above steering algorithms.

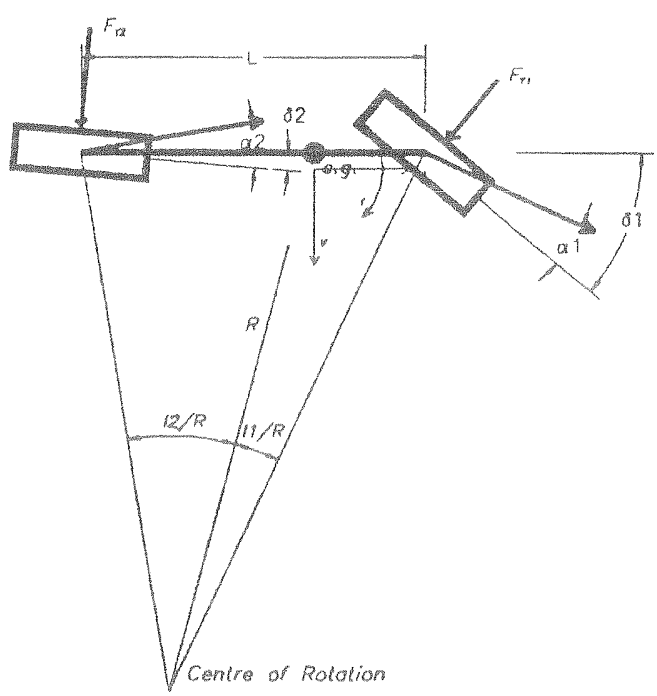

Figure 1 Two Degree of Freedom Bicycle Model 
Figure 1 shows the wo-degree of tredom bicycle model whth boh axles steered. The equations of motion for this model can be expressed as a state-space equation:

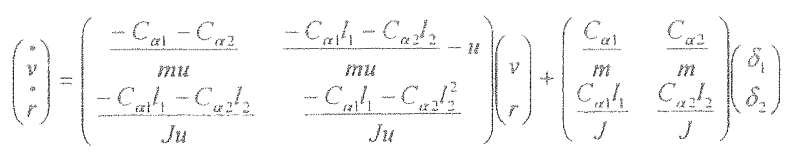

From this state-space system the transfer function of the body sidestip angle to the steering wheel angle can be obtained [7]. This assumes a constant ratio, $K$, between front and rear wheel steering angles.

$$
\frac{\beta(s)}{\Delta_{s w}(s)}=\frac{1}{n} \frac{G_{\beta}+K G_{\beta}+\left\{G_{\beta} \tau_{\beta}+K G_{\beta} \tau_{\beta}\right\}}{\left(1+\frac{2 \zeta}{\omega_{n}} s+\frac{1}{\omega_{n}^{2}} s^{2}\right)}
$$

In this equation:

$$
\begin{gathered}
G_{\beta}=\left(\frac{\left.-l_{2}-\frac{l_{1} u^{2} m}{C_{\alpha 2} L}\right), G_{\beta}^{\prime}=\left(\frac{l_{1}-\frac{l_{2} u^{2} m}{C_{\alpha 1} L}}{\left(1+k u^{2}\right) L}\right)}{\left(1+k u^{2}\right) L}\right) \\
\frac{25}{\omega_{n}}=\frac{\frac{J}{C_{\alpha 2} L}}{\left(1+k u^{2}\right) \frac{l_{2} u^{2} m}{C_{\alpha 2} L}} \\
\frac{1}{C_{\alpha 1} C_{\alpha 2} L^{2}} \\
\omega_{n}^{2}
\end{gathered}
$$

The steady-state gain in sideslip angle is then given by:

$$
\begin{gathered}
\left(\frac{\beta(s)}{\Delta_{s w}(s)}\right)_{s s}=\frac{1}{n}\left\{G_{\beta}+K G_{\beta}^{\prime}\right\} \\
\left(\frac{\beta(s)}{\Delta_{w w}(s)}\right)_{s s}=\frac{1}{n}
\end{gathered}
$$

If we set the steady-state gain $=0$, then we can solve for K:

$$
R=\frac{h_{1}+\frac{m_{1}}{C_{a 2}\left(l_{1}+l_{2}\right)} U_{0}^{2}}{l_{1}+\frac{m l_{2} l^{2}}{C_{a l}\left(h_{1}+l_{2}\right)} U_{0}^{2}}
$$

Therefore, K may be set to a value that will give zero body sideslip angle at steady state at a certain speed (Figure 2). By allowing $K$ to vary with $U$, then the steady-state sideslip angle may be kept at zero over the full range of vehicle speed.

At very low speed $(u \rightarrow 0)$, the formula for $K$ reduces to simply $I_{2} / I_{1}$. For this car, $I_{2} / I_{1}=-0.5$. Therefore, the desired steer ratio at very low speed equals -0.5 . Hence the desired steer ratio depends only on the position of the center of gravity along the wheelbase. This makes sense, as at very low speeds, slip angles will be very low, so the cornering stiffnesses of the axles will become irrelevant.

As vehicle speed increases, $K$ becomes less negative and equals zero at a speed $u=-12 \mathrm{~m} / \mathrm{s}$ for this vehicle. It then continues increasing with vehicle speed and converges on a value above 0.8 . II can be shown that in the limit as $u \rightarrow$ infinity, $K$ tends to simply $K=\frac{l_{1} C_{\alpha 1}}{\left|l_{2}\right| C_{\alpha 2}}$. In this case, $K_{\text {inf }}=0.848$.

This trend for $K$ to be negative at low speeds and positive at high speeds is consistent with the concept of opposite-phase steering for improved maneuverability at low speeds and same phase steering for enhanced stability at high speed [10], [11]. The curve of $K$ against vehicle speed is used in implementing the speed. sensing algorithm in the DADS model.

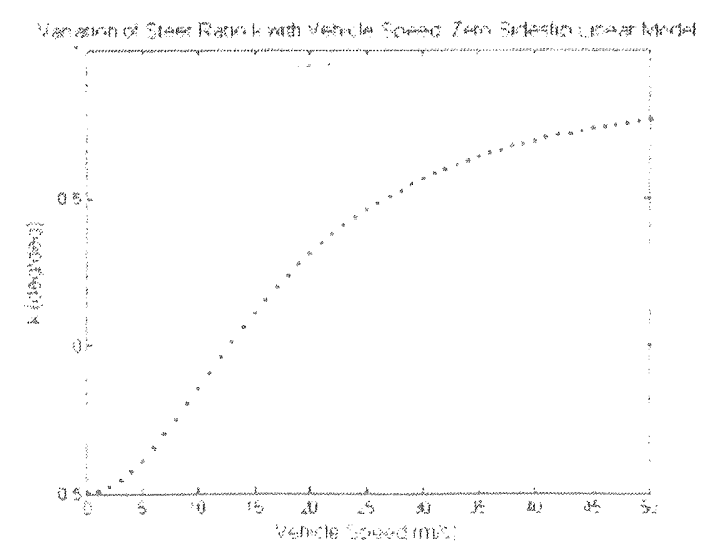

Figure 2 Speed Sensing Algorithm for 4 WS 
The Transter Functions of Yaw Fate and Lateral Acceleraton are derived rom the State Space Equation [7. They have the following toms:

$$
\begin{aligned}
& \left.\frac{r(s)}{\Delta_{s w}(s)}=\frac{1-K}{n} \frac{G_{r}}{\left(1+\frac{2 \zeta}{\omega_{n}} s+\frac{1}{\omega_{n}^{2}} s^{2}\right.}\right)^{\left(1+\tau_{s} s\right)} \\
& \left.\frac{A(s)}{\Delta_{s}(s)}=\frac{1-K}{n} \frac{G_{n}}{\left(1+\frac{2 \zeta}{\omega_{n}} s+\frac{1}{\omega_{n}^{2}} s^{2}\right.}\right)^{\left(1+\left(1+\lambda_{1}\right) \pi_{1} s+\left(1+\lambda_{2}\right) \tau_{2} s^{2}\right)}
\end{aligned}
$$

Where:

$$
\begin{aligned}
& G_{r}=\frac{u}{\left(1+k u^{2}\right) L} \\
& G_{A}=\frac{u^{2}}{\left(1+k u^{2}\right) L} \\
& \tau_{r}=\frac{m l_{1}}{C_{\alpha 2} L} \\
& \tau_{1}=\frac{-l_{2}}{u} \\
& \tau_{2}=\frac{J}{C_{\alpha 1} L} \\
& \lambda_{1}=\frac{K}{1-K} \frac{\tau_{1}+\tau_{1}^{\prime}}{\tau_{1}} \\
& \lambda_{2}=\frac{K}{1-K} \frac{\tau_{2}+\tau_{2}^{\prime}}{\tau_{2}}
\end{aligned}
$$

We can see from these results that the yaw response characteristics do no vary significantly with steer ratio they will be the same as in the 2WS case. Only the lateral acceleration response characteristics of the system are affected by implementing 4 WS.

When the rear wheels are steered in the same direction as the front wheels (i.e. $0<K<1$ ), then $\lambda_{1}, \lambda_{2}>0$ in equation 11. The lead time constants, in the lateral acceleration transfer function increase with $\lambda$ and therefore, the delay in the lateral acceleration response decreases.

Thus, we can see that same-phase steering of the rear wheels can reduce the phase lag of the lateral acceleration response.
The inear model was also implemented in the SMULINk sotware. This model takes the form of a block diagram, which solves the equations of motron of the vehicle. In these tests, the vehicle was drven at a constant speed and steer input was rapidly ramped up to a specined value, and then held constant. The steer angles applied to the three SMULINK models (FWS, SP and $O P$ ) are such that they will give the same steady state tuming radius.

\section{NONLINEAR MODELING}

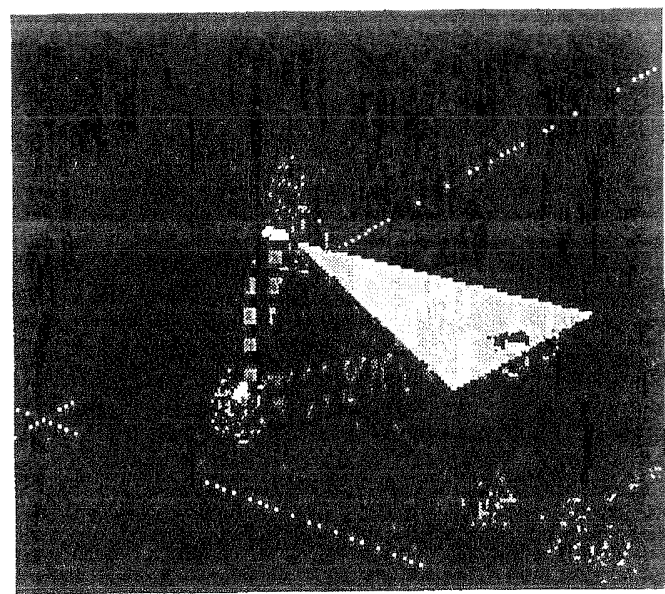

Figure 3 Front Leff Wheel station in DADS Model

The DADS model is a full 3D model of all the vehicle components. Double wishbone suspension is modeled at each of the four wheel stations. Figure 3 shows the front left wheel station. The tire characteristics are obtained from data made available by a commercial manulacturer for the Formula SAE series. An adaptive steering system is employed, which steers the vehicle based on its deviation from an ideal path.

The model was subjected to various handing tests. These lests were chosen to reflect both handing tests commonly carried out on vehicles, and the type of challenges to which this type of racing car would be subjected in competition. The steering systems which were subjected to these tests were the three above FWS, SP and OP, and also a speed-sensing (SS) algorithm which had been generated from the MATLAB modeling. 


\section{STEP STEERMG WPU}

In this lest, the vehicle is inilially runing straight, and then a steer input is rapidy appled and kept constant. The vehicle speed and steer angle are chosen to keep lateral acceleration below $0.4 \mathrm{~g}$. This test is examined using the SWMULINK model. It gives both an initial transient response and then steady-state response. The data from this test was uselul in validation of the DADS model.

\section{LANE-CHANGE TEST}

This is an 150 standard test in which the vehicle is required to negotiate a double lane change maneuver. Three sets of cones are laid out in the form of three lanes. The second of these lanes is offset $3.5 \mathrm{~m}$ from the first and third. The vehicle must maneuver between these lanes without touching any cones. This test was examined using the DADS model.

\section{SLALOM TEST}

This test is based on the slalom section of the course used in the Formula SAE event. The rules of the Formula SAE competition state that the slalom will consist of cones in a straight line with $7.62 \mathrm{~m}$ to $13.19 \mathrm{~m}$ spacing. The test in this project used slalom with $10 \mathrm{~m}$ between cones. This test was also examined using the DADS model.

\section{RESULTS}

\section{LINEAR TEST RESULTS}

Table 1 Linear Test Resuls

\begin{tabular}{|c|c|c|c|}
\hline \multirow{2}{*}{$\begin{array}{l}\text { Sreving } \\
\text { System }\end{array}$} & \multicolumn{3}{|c|}{ SWULINK TESLS a $10 \mathrm{~m} / \mathrm{s}$} \\
\hline & $\begin{array}{l}\text { Sidesing } \\
\text { Velociny } \\
(\mathrm{m} / \mathrm{s})\end{array}$ & $\begin{array}{l}\text { Response } \\
\text { Tine }(\mathrm{s})\end{array}$ & $\begin{array}{l}\text { Peak silp } \\
\text { Ange } \\
\text { (deg) }\end{array}$ \\
\hline ms & 0.04 & 0.31 & 0.54 \\
\hline $5 P$ & 0.34 & 0.31 & 0.86 \\
\hline OP & -0.06 & 0.29 & 0.42 \\
\hline 55 & - & - & $\infty$ \\
\hline
\end{tabular}

\section{Sideslip Velocity}

It is recognized in the literature that a steady-state sideslip velocity of zero is desirable when the vehicle is undergoing a turn [7], [8]. This is in order that the vehicle is pointing in the direction in which it is traveling. In the initial stage, the sideslip velocity is always positive. This means that the vehicle is lacing out of the tum. The reason for this is that silp angles are developed at the from wheels immediaty once the steer input is applied. It takes a shon time Ior the rear axle slip angles to increase to their steady-state value

If was found in this research that increasing the vehicle speed caused the sideslip velocity of all three vehiches to become more negative; in other words the body is lumed more lowards the inside of the comer. This agrees with the trend identified in [7].

As a general trend, we can see that the sidesip velocity of the OP model tends to be negative, or lacing into the tum, and the sideslio velocity of the SP model tends to be positive, or facing out of the turn (Figure 4).

\section{Yaw Rate}

Figure 5 shows the yaw rate response of the three vehicles at $10 \mathrm{~m} / \mathrm{s}$. The steady state yaw rate is the same for all three. This is because the vehicle speed and the turn radius are the same, so as $p=u / R$, the yaw rate will also be the same. The steady-state yaw rate increases with speed for the all the test vehicles. Again, this makes sense, as the yaw rate is directly proportional to the vehicle speed.

\section{Slip Angles}

For the FWS vehicle (Figure 6), the slip angle at the front axle increases rapidly to a value close to the applied steer angle. This slip angle produces a side force that initiates yaw motion of the vehicle. The yaw motion reduces the front slip angle and increases the rear slip angle until steady state is reached. In steady state, the front slip angle is larger than the rear slip angle. The reason for this is that the front cornering stiffness is much less than the rear. To balance moments about the center of gravity, the front cornering force needs only to be half of the rear cornering force, as the center of gravity is wice as far from the front as from the rear axle. However, the front comering stifness is less than half the rear cornering stifness. and so a greater slip angle is required.

In the SP case (Figure 7), the slip angles at the front and rear both increase from zero to their steady-state values. This shows that in the transient part of the maneuver, both axles develop comering forces in the same direction. For the OP scenario (Figure 8), the rear slip angles develop initially in the opposite direction to the front slip angles. This will give rapid yaw response.

The SP system has the highest peak slip angle, while the OP system produces the lowest peak slip angle. In both cases, the front wheels experience these peak slip angles. 


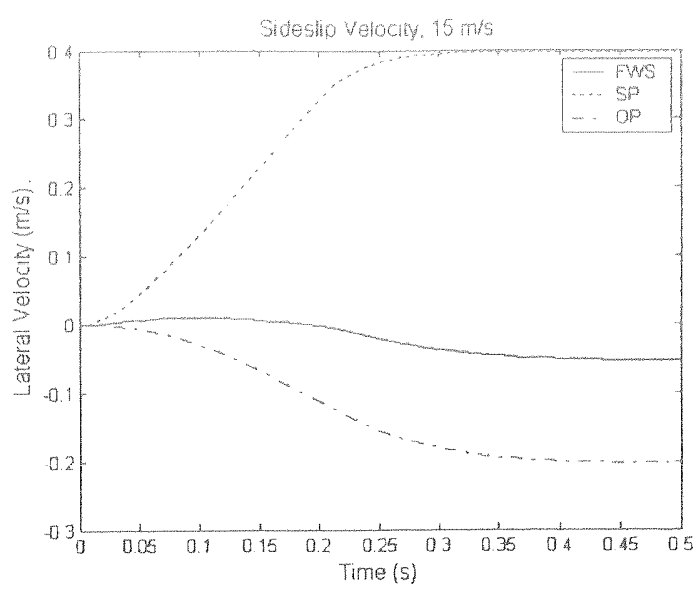

Figure 4 Sideslip Valocity Response during Step Steer at $15 \mathrm{~m} / \mathrm{s}$

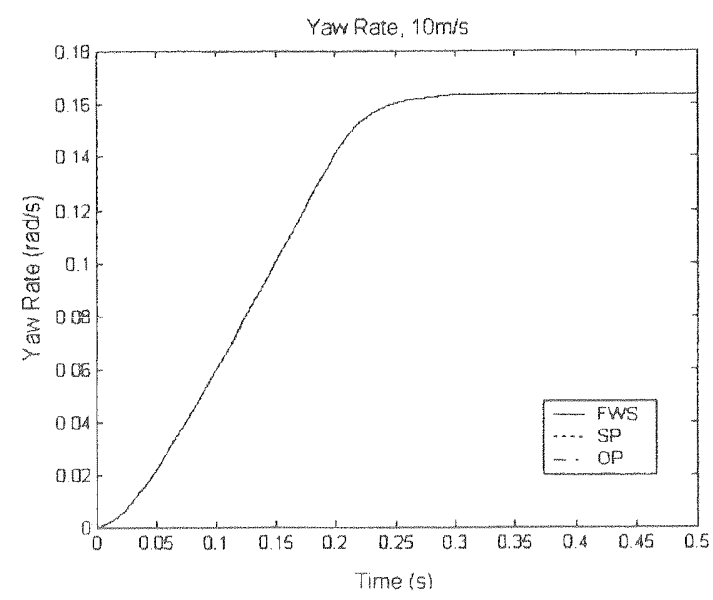

Figure 5 Yaw Rate Response durng Step Steer al $10 \mathrm{~m} / \mathrm{s}$

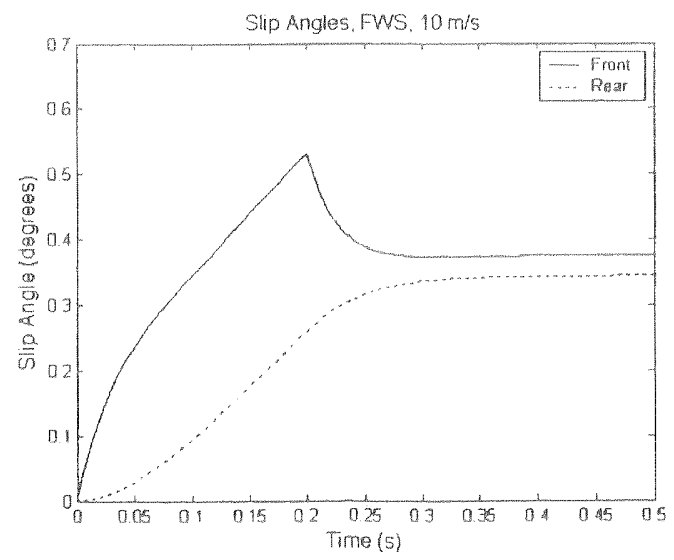

Figure 6 Stip Angle Fesponse durng Step Srear, FW

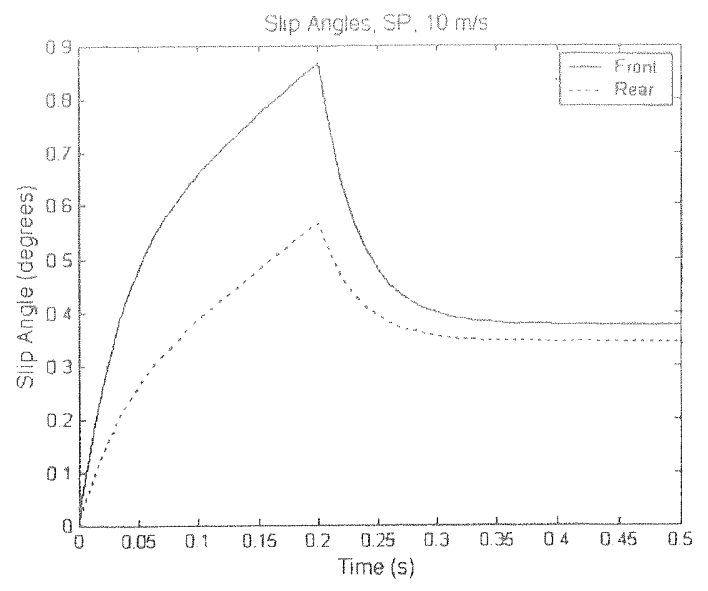

Figure 7 Slip Angle Fesponse during Step Steer, sp

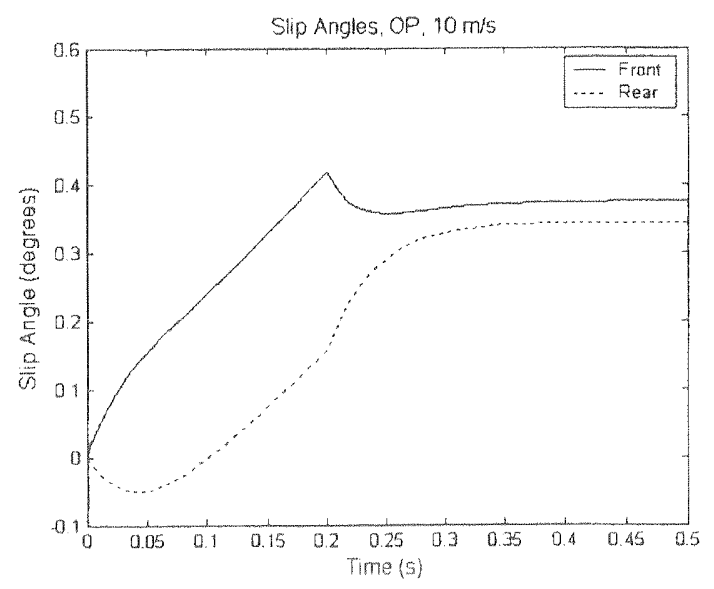

Figure 8

Slip Angle Hesponse during Step Steer, OP 
NONLINEAR MODEL RESULTS

Table 2 Lane Change Test Results

\begin{tabular}{|l|l|}
\hline $\begin{array}{l}\text { Steering } \\
\text { System }\end{array}$ & $\begin{array}{l}\text { Lane Change } \\
\text { Speed (m/s) } \\
\text { (position) }\end{array}$ \\
\hline PWS & $28\left(3^{\text {rd }}\right)$ \\
\hline SP & $31\left(2^{\text {d }}\right)$ \\
\hline OP & $27\left(4^{\text {h }}\right)$ \\
\hline
\end{tabular}

The worst performance in the lane change is given by the opposite-phase system, while the speed-sensing sysiem can negotiate the tesi at the highesi speed. The wheel paths of each system at the highest speed at which that system could negotiate the test were examined. These paths yielded information as to what was the reason for failure in the test. In the case of the FWS and OP systems, they fail the test because the rear right wheel (wheel 4) crosses the lane boundary. It is clear that the front wheels are following the path better than the rear wheels, which slide out giving an oversteer characteristic. This oversteer is counteracted in the case of the SP and SS systems by same-phase steering of the rear wheels.

Figures 9 to 12 show the variation of various parameters over the test for all the steering systems. These are for a lane change maneuver at $25 \mathrm{~m} / \mathrm{s}$.

The yaw response for the different systems is shown in Figure 9. The OP system gives the quickest yaw response, but also the highest peak. The model seems to weave in the midsection of the test, where the yaw rate is unnecessarily reversed. The peak yaw rate is much lower for the SP and SS systems, and they do not exhibit the weave mode in the midsection.

Figure 10 shows the lateral acceleration response of the four systems. The same-phase and speed sensing vehicles develop lateral acceleration quickest and have a relatively low peak lateral acceleration. This is because all the steered wheels act in the same direction to produce lateral forces in the same direction. The FWS and OP systems are slower to develop lateral acceleration. This is because, in the case of the FWS system, slip angles are only developed at the rear wheeis due to the lateral movement induced by the front wheel steering angle. In the case of the OP system, the rear wheels actually work in the opposite direction to the front. The peak lateral acceleration produced by the opposite-phase system is the highest of the four systems. At its highest the lateral acceleration generated by the vehicle with $O P$ steering is above $1.5 \mathrm{~g}$, which is certainly pushing the tires to their limits.
Figure 11 shows the lateral velocity response. The lateral velocity of the OP system is highest, and the SS system succeeds in reducing the lateral velocity from the FWS response.

Examining the steer angle of the left front wheel during the test (Figure 12), it is shown that the OP system produces a quicker yaw response, which points the vehicle in the desired direction quicker, and thus the steer angle necessary is lower. However, it is also apparent in the midsection and in the final section of the test that the driver has to reverse the steering in order to keep the vehicle under control. This is not a desirable situation. The steer angle of the SS system is lower than the SP system.

Table 3 Slalom Test Results

\begin{tabular}{|l|l|}
\hline $\begin{array}{l}\text { Steering } \\
\text { System }\end{array}$ & $\begin{array}{l}\text { Slalom } \\
\text { Speed (m/s) } \\
\text { (position) }\end{array}$ \\
\hline FWS & $16\left(2^{\text {nd }}\right)$ \\
\hline SP & $14.5\left(3^{\text {rd }}\right)$ \\
\hline OP & $14\left(4^{\text {in }}\right)$ \\
\hline SS & $16.5\left(1^{\text {st }}\right)$ \\
\hline
\end{tabular}

Figures 13 to 15 show the variation of various parameters over the test for all the steering systems. These are for a slalom maneuver at $10 \mathrm{~m} / \mathrm{s}$. At this speed the SS system has a K of -0.2 .

Figure 13 shows the lateral acceleration responses of the four systems. The responses are similar, with the $\mathrm{OP}$ system having the highest peak value. The SP system has the lowest lateral acceleration.

Figure 14 shows the lateral velocity response of the four systems in slalom testing. In contrast to the lanechange results, here we see that the SP system gives the largest lateral velocity, while the OP system gives a relatively low lateral velocity response. The FWS and SS system give lower values still, and these responses are similar except that they are the reverse of each other. This means that, in the case of the FWS systern, the vehicle is facing towards the outside of the turn, while in the case of the SS system, the vehicle is facing inwards of the path.

Figure 15 shows the yaw rate response. We see once again that the OP system has the quickest yaw response, and the highest peak yaw value. The SS system has both the slowest yaw response and the lowest peak value. 


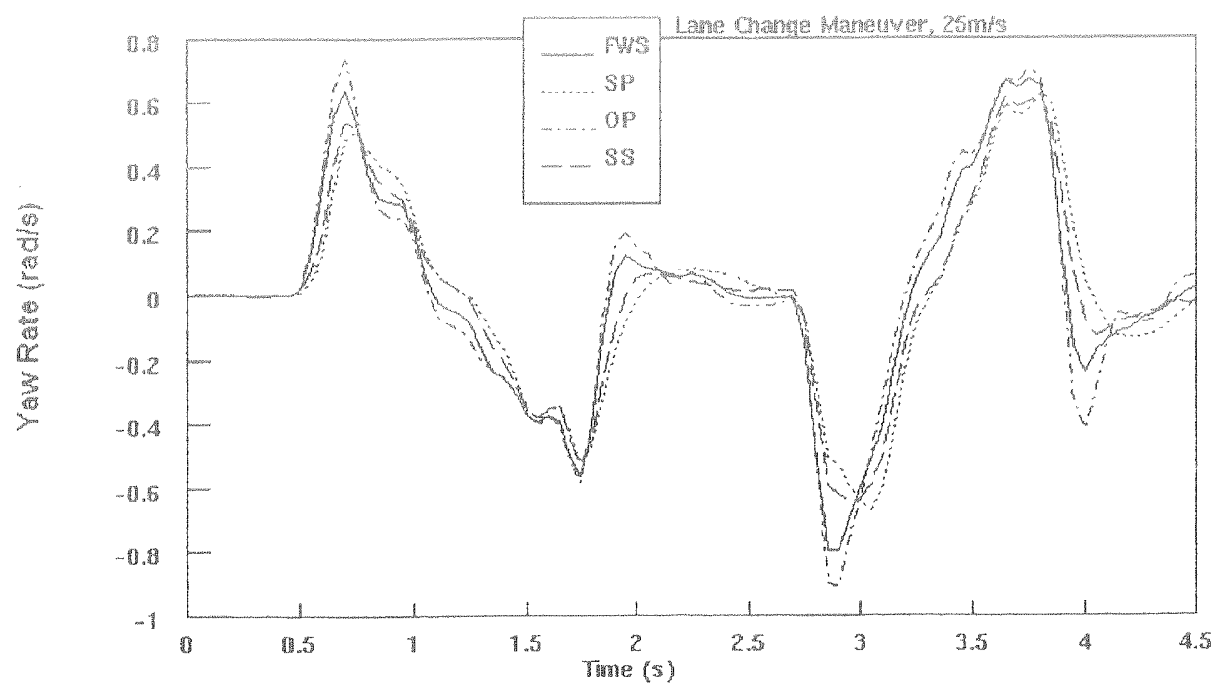

Figure 9 Yaw Rate during Lane Change Test

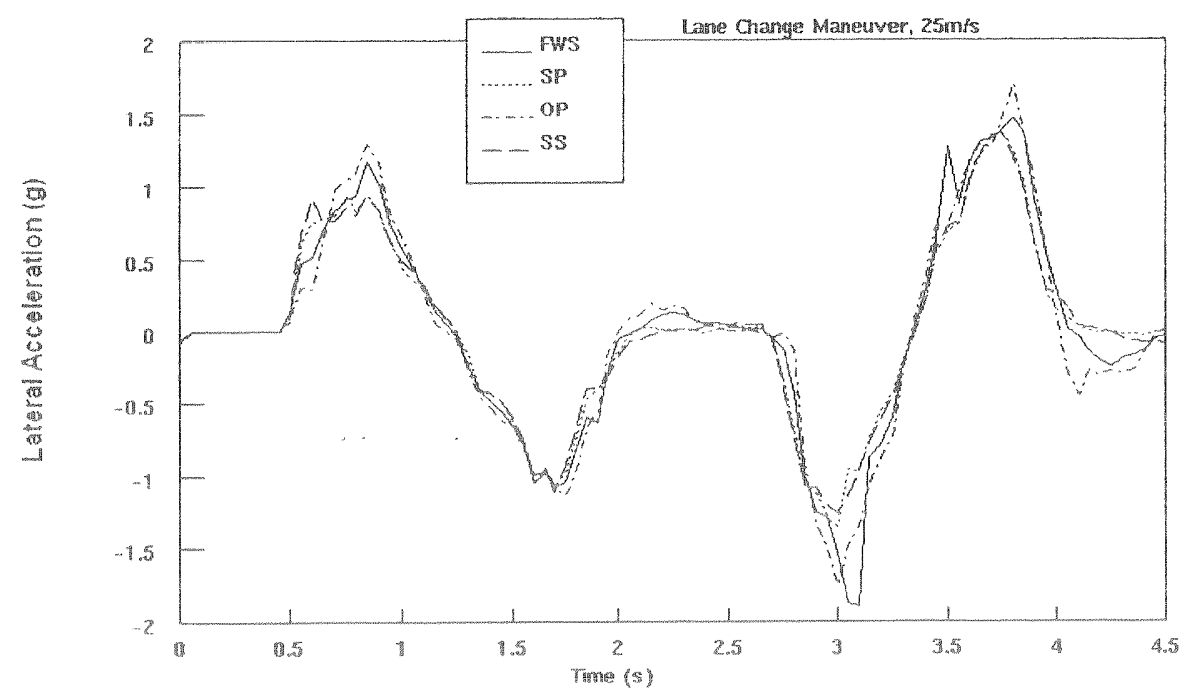

Figure 10 Lateral Acceleration during Lane Change Test 


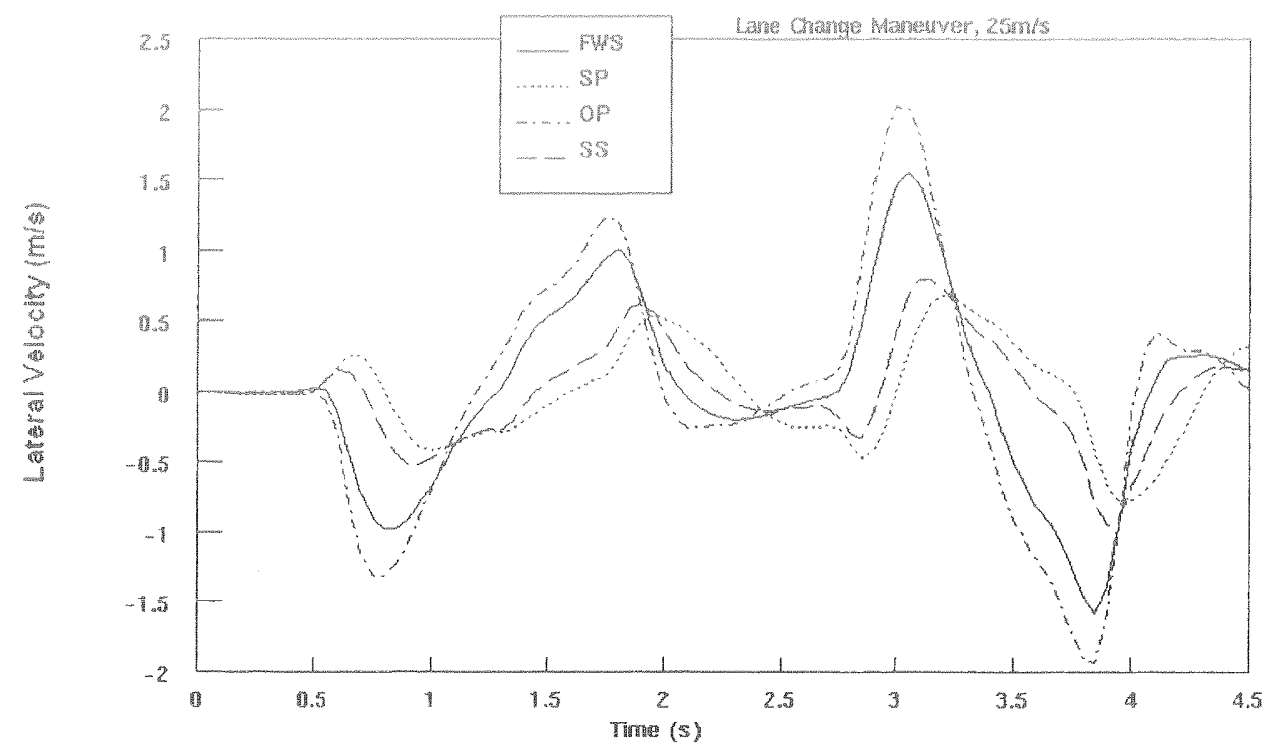

Figure 11 Lateral Velocity during Lane Change Test

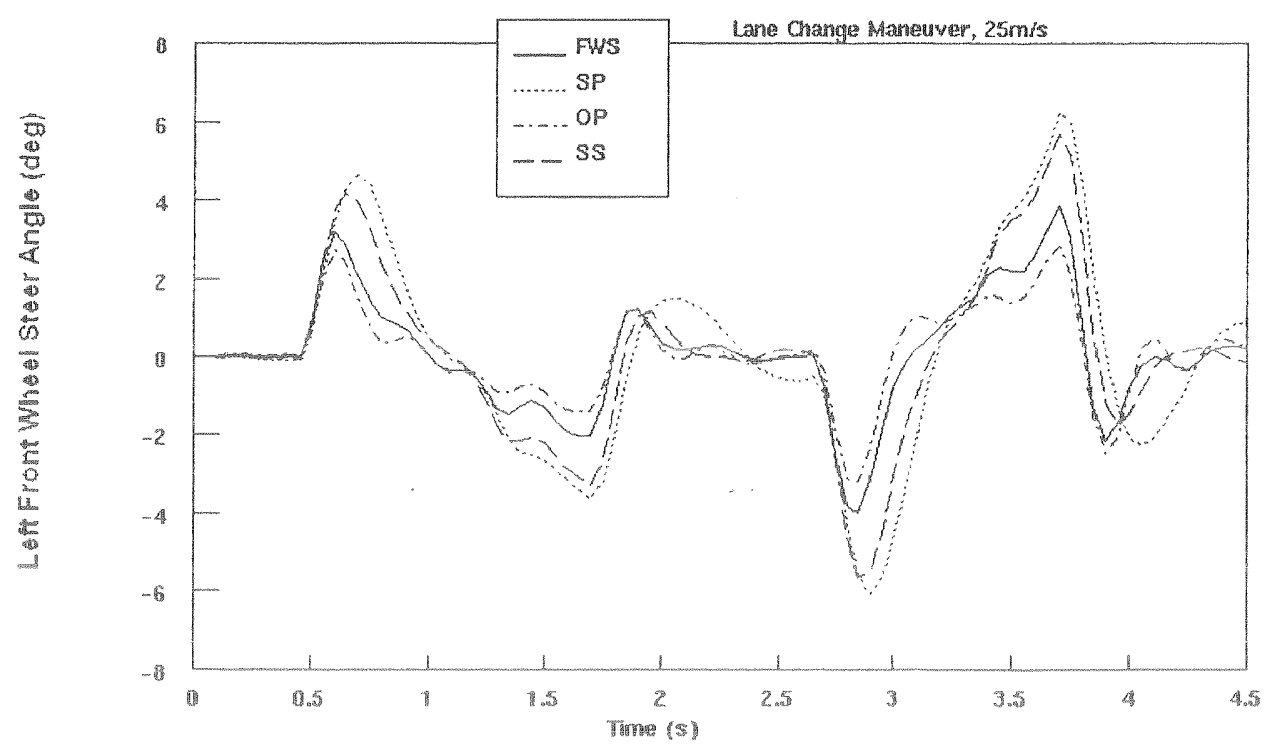

Figure 12 Steer Angle dung Lane Change Test 


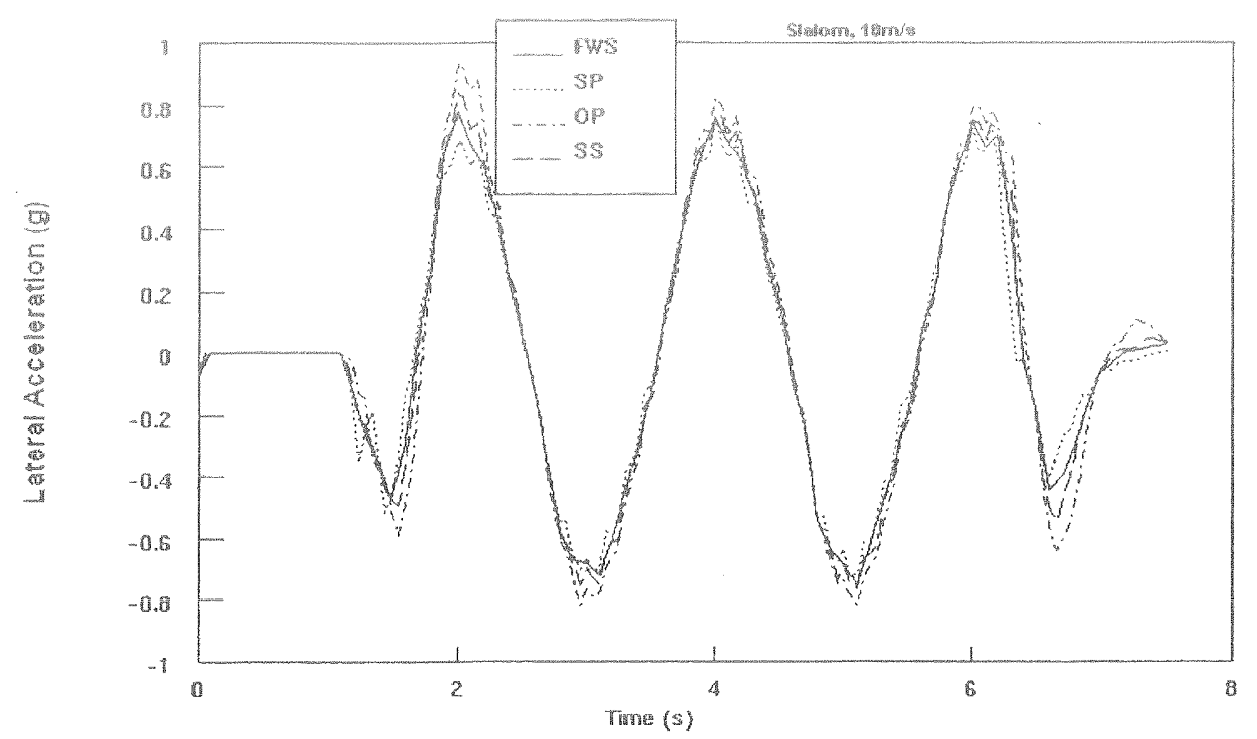

Figure 13 Lateral Acceleration in Slalom Test

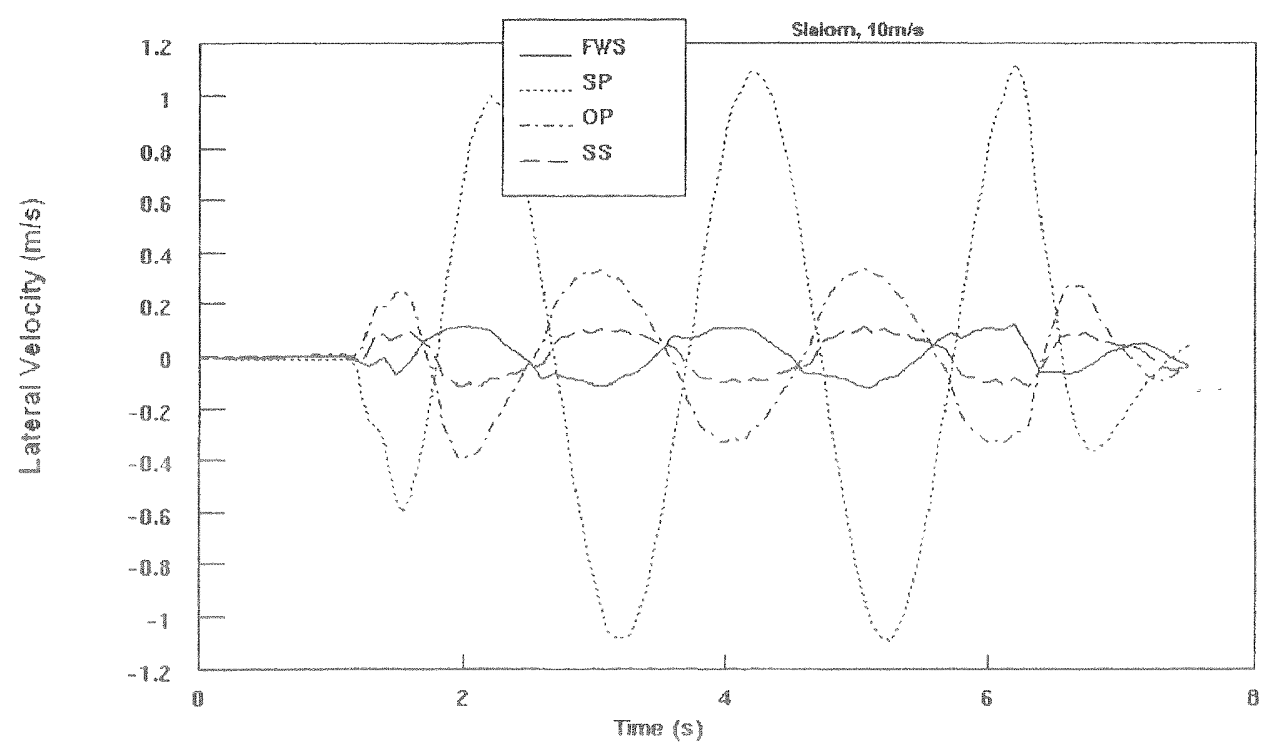

Figure 14 Lateral Velocity in Slalom Test 


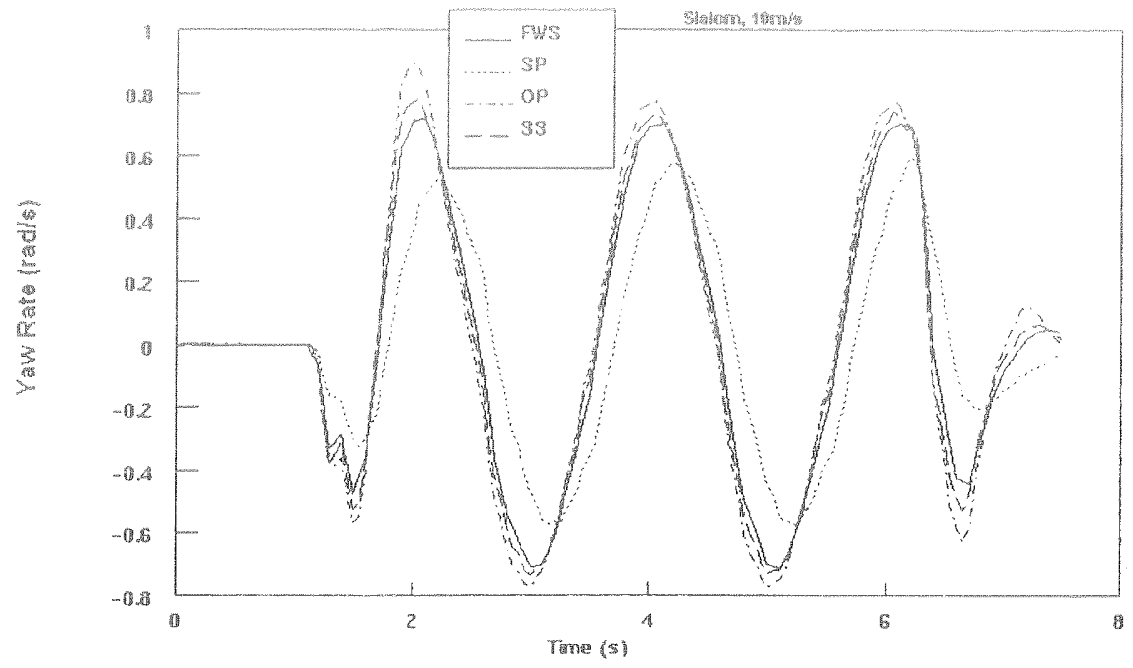

Figure 15 Yaw Fate in Slalom Test 


\section{COMPARISON OF SVSTEMS}

The FWS system has a reletvely low sideslio velocily at the thee speeds tested by the SMUUMK model. At $10 \mathrm{~m} / \mathrm{s}$, its yaw rate reaches steady state after 0.31 seconds. The peak slip angle obtained at $10 \mathrm{~m} / \mathrm{s}$ is 0.54 degrees. In the DADS tests, the FWS system is capable of negotiating the lane-change course at $28 \mathrm{~m} / \mathrm{s}$ and the slatom at $16 \mathrm{~m} / \mathrm{s}$. This gives it a ranking of $3^{\text {th }} \mathrm{in}$ the lanemchange and $2^{\text {nd }}$ in the slalom courses.

The SP system has quite a high posilive sideslip velocily in the SIMULINK tests. This means that it is facing towards the outside of the tum. lts yaw response lime at $10 \mathrm{~m} / \mathrm{s}$ is similar to the FWS model at $0.31 \mathrm{~s}$. The SP model exhibits very high peak slip angles compared to the FWS and OP models. At $10 \mathrm{~m} / \mathrm{s}$ the value is 0.86 degrees. At $15 \mathrm{~m} / \mathrm{s}$, the $S P$ model exhibits a peak lateral acceleration at the front axle above $0.4 \mathrm{~g}$, so the linear model is no longer valid. It is the only one of the three vehicles to exhibit this behavior at this speed. The SP system performs well in the DADS lane change tests, negotiating the test at $31 \mathrm{~m} / \mathrm{s}$. However, its performance in the slalom lest is worse than the FWS system, achieving a top pass speed of only $14.5 \mathrm{~m} / \mathrm{s}$.

The OP system has a negative sideslip velocity in the SIMULINK tests. This means that it is facing inwards of the turn. Its yaw response time is quicker than the FWS and $O P$ systems, at $0.29 \mathrm{~s}$ at a speed of $10 \mathrm{~m} / \mathrm{s}$. This system displays quite low peak slip angles, approximately 0.42 degrees at $10 \mathrm{~m} / \mathrm{s}$.

The system performs badly in the DADS lane change lest, producing a pass speed lower than the FWS system of $27 \mathrm{~m} / \mathrm{s}$. This is because the rear wheels tend to slide towards the outside of the lurns in any case, but with the OP system this effect is accentuated. The vehicle fails the test in the final section due to the rear axle sliding. The OP system does not perform well either in the low-speed slalom test, having the worst petormance of the four systems.

The SS system was investigated only in the DADS nonlinear model. It gives the best performance of all four systems in both the lane-change and slalom lests and gives the best compromise beween high-speed and low-speed performance.

\section{CONCLUSION}

The algorithm developed using the linear model has been shown to be effective in the nonlinear region of the vehicle dynamics. The linear model has been confirmed as a useful tool in producing algorithms for the nonlinear case.
One of the aims of this research was to identify whether a simple linear ratio between front and rear steer angle would suffice to improve the yaw response of this ype of vehicle. This would be the most easily manuractured solution and could be simply implemented using a mechanical gearing between the front and rear steening racks. Complexty and therefore production cost would be low and the system would be easily maintained. However, it is clear from the results obtained that a more complex system is necessary. A consistent improvement in the yaw response of the vehicle, in low speed as well as high speed maneuvers, requires a variable ratio between the front and rear steer angles. The speed-sensing controller investigated in this project fultils these objectives. II improves vehicle performance both in the relatively high-speed lane change maneuver and in the low speed slalom.

It is clear that in the lane change test at $33 \mathrm{~m} / \mathrm{s}$, the $S S$ system is operating at the limits of the tires adherence to the road surface. The falure mode identified suggests that while the tront wheels are following the path adequately, the rear wheels are sliding. This is a case in which Direct Yaw Control could be useful. Application of an outward yaw moment could remedy the situation. Further vehicle modeling and analysis could assess the possible benefits of this strategy. It must be remembered, however, that any system implemented on a Formula SAE car must not only improve the dynamic response of the vehicle, but also be efficient in terms of adding minimum cost and mass to the vehicle.

\section{REFERENCES}

[1] Ahring, E. and Mitschke, M. (1995) "Comparison of All-Wheel Steerings in the System Driver-Vehicle", Vehicle System Dynamics, 24 (1995), pp. 283-298

[2] Cho, Y. H. and Kim, J. (1995) "Design of Optimal Four-Wheel Steering System", Vehicle System Dynamics, 24 pp. 661-682

[3] Furukawa, $Y$ and Abe, M. (1997) "Advanced Chassis Control Systems for Vehicle Handing and Active Safety", Vehicle System Dynamics, 28, pp.59-86

[4] Yaniv, O., (1997) "Robustness to Speed of 4WS Vehicles for Yaw and Lateral Dynamics". Vehicle System Dynamics, 27 (1997), p0.221-234

[5] Fuita, K. et al (1998) "Development of Active Rear Steer System Applying $H_{\text {w }}$ H synthesis", SAE Paper 981115

[6] Akita, R. (1992) "Present and Future of Four-Wheel Steering Technology", JSAE Review Vol.13, No.1, pp. $52-57$ 
[7] Furukawa, Y., of al (1989) "A Revew of Four-Whed Steering Sudies mom the Vievpoint of Vehicle Dynamics and Control", Vehicle System Dynamics, 18 , po. $151+186$

[8] Sano, S. (1988) "Evaluation of Four Wheel Steering Technology and its Future Prospects", WSAE Review Vol. 9. No. 3, pp. 4. - 7(1988)

[9] Kramer, K., Cakins, D. E. (1994) "Lateral response of a Formula SAE car", SAE Paper 942523

[10] Sano, S., et al (1986) "Four-Wheel Steering System with rear wheel steer angle controlled as a function of steering wheel angle", SAE Paper 860625 (1986)

[11] Takiguchi, T. et al (1986) "improvement of Vehicle Dynamics by Vehicle-Speed-Sensing Four-Wheel Steering System", SAE Paper 860624 (1986)

[12] Abe, M. (1999) "Vehicle Dynamics and control for improving handling and active safety: from four-wheel steering to direct yaw-moment conirol", Proc IMechE Vol 213 Part K, pp. 87-101

[13] Koibuchi, K. et al, (1996) "Vehicle Stability Control in Limit comering by Active Brake", SAE Paper 960487
[34] Nagai, M, et al (1997) "Integrated Control of Actve Rear Whed Steering and Dred Yaw Moment Controf: Vehicle System Dynamics, 27, pp.357-370

\section{COMIAT}

sean.timoney@ucdie; colm.okane@ucdie

\section{ADDITIONAL SOURCES}

Dixon, John C. (1996) "Tires, Suspension and Handing", $2^{\text {nd }}$ Ed., New York, Society of Automotive Engineers.

Gillespie, Thomas D. (1992) Fundamentals of Vehicle Dynamics. Society of Automotive Engineers, Inc.

SAE (1976) Vehicle Dynamics Teminology - SAE J670e. Sociely of Automotive Engineers, Inc.

Milliken, W. F. and Milliken, D.L. (1995) "Race Car Vehicle Dynamics", SAE R-146, Society of Automotive Engineers, Warrendale, Pa., 1995

McBeath, S. (2002) "Four Wheel Steering - Nipped in the Bud", Racecar Engineering, November 2002, pp. 5462 